Minasian, C. C., Wallis, C. \& Bush, A. (2007) Mannitol as a mucolytic in cystic fibrosis. $J R S o c$ Med 100 (Suppl. 47), 53-56.

Saiman, L., Marshall, B. C., Mayer-Hamblett, N., Burns, J. L., Quittner, A. L., Cibene, D A., Coquillette, S., Fieberg, A. Y., Accurso, F. J. \& other authors (2003). Azithromycin in patients with cystic fibrosis chronically infected with Pseudomonas aeruginosa: a randomized controlled trial. JAMA 290, 1749-1756.

DOI 10.1099/mic.0.024752-0

\section{Sugar sweet and deadly: author's response}

Drs Reid and Bell provide thoughtful and informative comments on our recent report (Bartholdson et al., 2008), which describes the production of exopolysaccharide (EPS) in the presence of mannitol, and other sugar alcohols, by the Burkholderia cepacia complex (Bcc). My co-authors and I are grateful for these insights. We would also point out that the role of EPS in the pathogenesis of Bcc may demonstrate additional idiosyncrasy and subtlety in these organisms relating to a suggested similarity between the Bcc and the characteristic conversion to a mucoid, alginate-producing phenotype observed in Pseudomonas aeruginosa during the chronic stages of infection in individuals with cystic fibrosis (CF). In our study, we were initially surprised to observe a lack of EPS biosynthesis in the highly virulent Burkholderia cenocepacia ET12 lineage. However, as we suggested, loss of mucoidy in $B$. cenocepacia isolates could provide a striking contrast with the pathogenesis of $P$. aeruginosa. Zlosnik et al. (2008) recently observed that isolates of $B$. cenocepacia are frequently non-mucoid, and also a surprising mucoid to non-mucoid conversion in sequential isolates from chronically infected patients. As they suggest, Bcc EPS could be responsible for the persistence of Bcc in CF airways, whilst loss of EPS could lead to enhanced virulence. The influence of this change in EPS phenotype on mannitol therapy in individuals with $\mathrm{CF}$, including CF-related diabetes, is unclear.

\section{John R. W. Govan}

Centre for Infectious Diseases, University of Edinburgh, Edinburgh EH16 4SB, UK

Correspondence: John R. W. Govan (john.r.w.govan@ed.ac.uk)

Bartholdson, S. J., Brown, A. R., Mewburn, B. R., Clarke, D. J., Fry, S. C., Campopiano, D. J. \&

Govan, J. R. (2008). Plant host and sugar alcohol induced exopolysaccharide biosynthesis in the Burkholderia cepacia complex. Microbiology 154, 2513-2521.

Zlosnik, J. E., Hird, T. J., Frankel, M. C., Moreira, L. M., Henry, D. A. \& Speert, D. P. (2008).

Differential mucoid exopolysaccharide production by members of the Burkholderia cepacia complex. J Clin Microbiol 46, 1470-1473.

DOI 10.1099/mic.0.027052-0 